\title{
Team Leadership on Capstone Design Project Teams
}

\section{Mr. Stephen W. Laguette, University of California, Santa Barbara}

Stephen Laguette is currently a Lecturer at the University of California, Santa Barbara in the College of Engineering in the Department of Mechanical Engineering (ME) and the Technology Management Program and is responsible for the undergraduate ME Capstone Design program. He received his BS, MS in ME from the University of California, Los Angeles. His professional career has included executive Research and Development management positions with a number of medical device companies. He has been responsible for the creation of complex medical devices with over sixteen US patents issued in a variety of surgical fields. He has been responsible for the identification of new technologies and the review of new business opportunities. His responsibilities have included transitioning projects into development and potential commercialization. He has identified and successfully created research programs with leading academic institutions and formed strategic alliances with other high technology companies. He has served as a Director with the Design in Engineering Education Division (DEED) for the American Society of Engineering Education (ASEE). His academic interests include Capstone design and the development of high performance student teams. He also remains active in the field of medical devices as a consultant for new ventures and investment firms.

Phone: (805) 893-2652 Email: laguette@engineering.ucsb.edu

Mailing address: Stephen W. Laguette Department of Mechanical Engineering University of California, Santa Barbara Santa Barbara, Ca 93106-505 


\title{
Team Leadership on Capstone Design Project Teams
}

\begin{abstract}
The Capstone design project is typically a team-based course experience at most engineering schools. The significance of student team dynamics and effective team performance continues to be of interest in the context of Capstone design projects and the desire to improve outcomes. As instructors, we are challenged to provide a learning experience while providing an environment for successful project outcomes. The effectiveness of the student team in addressing the design project is a significant factor in successful project outcomes and a successful student experience.

Successful student teams should include enthusiastic, motivated and engaged students as they must address the project over the academic year of the Fall, Winter and Spring quarters. The student team should also include satisfactory skills, technical or academic expertise as well as mutual accountability for each project. The importance of satisfactory team leadership is little understood in the Capstone environment. It is important that awareness and guidance is offered to the students and teams to better ensure successful project outcomes and student experience.
\end{abstract}

Team leadership and organizational team performance in terms of improved productivity continues to be of interest in the industrial setting. Student team leadership in an academic setting creates a different and perhaps an even more challenging situation due to a lack of experience and the lack of direct authority by a designated or selected student team leader.

To better understand team dynamics, Self Assessment, Team Assessment, Team Leader and Team Dynamics surveys of Capstone design teams has been conducted. High Performance and Underperforming teams based upon project outcomes and team dynamics has been identified with the assistance of independent faculty. The team dynamics and team leadership for these teams will be further examined.

This paper will provide a qualitative assessment of the demonstrated team leadership to better understand the role and importance of team leadership on Capstone design teams. Guidance will be developed based upon these assessments regarding team leadership for Capstone design teams. It is believed that increased awareness may improve team effectiveness. 


\section{Introduction}

A successful Capstone design program including companion design courses has been developed $^{1,2}$ that has become an integral and important component of the Mechanical Engineering (ME) curriculum. Attention continues to be focused upon the formation of student teams and the selection process in the hopes of developing High Performance student teams ${ }^{3,4}$ and successful project outcomes ${ }^{5}$. Successful student teams should include enthusiastic, motivated and engaged students as they must address the project over the academic year of the Fall, Winter and Spring quarters. The student team should also include satisfactory skills, technical or academic expertise as well as mutual accountability for each project.

Our Capstone design program has established Industry and Research partnerships and support that provide an array of interesting and challenging projects each year. Our typical class size is between 68 and 110 senior ME students resulting in 14 to 22 projects and teams each year. The effectiveness of the student team in addressing the design project is a significant factor in successful project outcomes and a successful student experience. We now have a wellestablished process for the formation of student teams and the selection process that involves the students. This process has now resulted in most teams as student-formed as compared with instructor-formed. This process has also now resulted in most students working on their most preferred project.

It was believed that by involving the students in the team selection process and the formation of teams that enthusiastic and engaged students would result in improved team effectiveness and outcomes. Detailed Team Assessment and Team Dynamics surveys have been conducted over the recent years that confirm team self-satisfaction and team performance has been very good overall. It was thought that this process would also provide an environment for High Performance teams to flourish and would possibly eliminate dysfunctional teams. Unfortunately, we have not been able to eliminate Underperforming teams and dysfunctional teams.

Attention continues to be focused upon improving student team performance and project outcomes. In addition to quarterly meetings with team leaders, an end-of-year discussion is conducted each year with the team leaders. Last year's team leaders voiced concern upon the project completion review regarding the lack of guidance that they had received in terms of their roles and responsibilities as a team leader. The role of team leader has been informal within the course structure. The concerns raised by the team leaders were very enlightening. Indeed, the role of team leader had been anticipated to be more of an administrative responsibility from a course and project perspective. The role of the team leader has been informal in an attempt to lessen the responsibility, pressure and anxiety of a leadership role and place a greater burden upon all team member roles and responsibilities. What has resulted, however, is a lack of guidance and support for this actual and practical leadership role.

The importance of satisfactory team leadership is little understood in the Capstone environment. It is important that awareness and guidance is offered to the students and teams to better ensure successful project outcomes and student experience. The intent of this paper is to examine the current informal team leadership role with a desire to provide improved guidance and support. It should be clear, however, that this is a qualitative assessment and review with a desire to provide 
improved guidance and support for the students and teams. The ultimate desire is an improved course experience for the students and teams with improved team performance and outcomes.

\section{Literature Review}

Team leadership and organizational team performance in terms of improved productivity continues to be of interest for industry and organizations. There is a wealth of literature regarding organizational teams and team leadership. It is important to understand that in the context of a student Capstone team that the role of team leader is somewhat unique. The leadership role on the Capstone project is temporary at best with no formal direct authority or responsibility on the team. There is also an absence of any formal overall hierarchal structure within a larger organization. For these reasons, the cited literature review is limited and has been more focused upon a general understanding of team leadership and improved team effectiveness.

A simple and effective description of a project team has been defined ${ }^{6}$ and is applicable for the approach under consideration:

"A team is a small number of people with complementary skills who are committed to a common purpose, performance goals, and approach for which they hold themselves mutually accountable.”

Using this definition, the driving factors for all project teams have also been described as follows ${ }^{6,7}$ :

- All teams need a sense of purpose and a clear cut mission.

- All teams need the mission to be broken down into meaningful performance goals for each team member to pursue.

- All teams need to develop certain work approaches, procedures and processes to ensure that they accomplish a task efficiently and effectively.

- All teams have to support the common mission and take their individual responsibility seriously to do their part in accomplishing a task.

- All teams need a mix of skills, experience, and expertise, in order to meet the challenges of the team task.

To further differentiate the qualities of High Performance team ${ }^{6,7}$ as compared with average teams:

- A deeper sense of purpose

- Relatively more ambitious performance goals

- Better work approaches and outcomes

- Mutual accountability

- Complementary skills and expertise

Unfortunately Underperforming teams have not been eliminated within the Capstone program. An accepted description of the five factors contributing to underperformance of a team has been described $^{8}$ :

- Absence of trust

- Fear of conflict 
- Lack of commitment

- Avoidance of accountability

- Inattention to results

Within the context of the Capstone course, a dysfunctional team is further defined ${ }^{4}$ from an Underperforming team as a team that is prevented from performing or completing expected activities due to conflict or behavior on the team by one or more team members.

An excellent overview of Team Leadership ${ }^{9}$ provides an excellent review of the literature and provides a focus on functional leadership. The paper argues that the success of the leader in defining team directions and organizing the team to maximize progress significantly contributes to team effectiveness. They argue that "effective leadership processes represent perhaps the most critical factor in the success of organizational teams."

An evaluation of team leaders by 6,000 team members in a variety of organizations has been reported ${ }^{10}$ and provides six dimensions critical for a team leader within an organization:

- Focuses on the Goal

- Ensures a Collaborative Climate

- Builds Confidence

- Demonstrates Sufficient Technical Know-How

- Sets Priorities

- Manages Performance

A functional approach to team effectiveness within an organization has been reported ${ }^{11}$ that focuses on five team functions:

- Team Objectives and Integration

- Decision making

- Managing meetings

- Implementing decisions

- Creating a healthy climate

The literature regarding team leadership in the academic setting ${ }^{12,13,14,15}$ is limited but does provide some useful insight.

A checklist of attributes of informal leadership adapted to student teams has been reported ${ }^{12}$

- Exerts influence on group processes (task)

- Maintains goal focus for self and group (task)

- Creates a collaborative atmosphere (relational)

- Exhibits technical competence (task)

- Exhibits fairness, humility, and trust (relational)

- Use creativity, reflection, and intuition (task and relational)

Within a very limited examination of student teams, the authors noted that successful informal leaders of student design teams excelled in the task arena. As reported, " They understood the 
problem, its requirements, and kept the team focused on the task. They often functioned as technical experts as they struggled with a difficult assignment.”

An important observation is also noted that one team had a dysfunctional relational leader with resulting poor team performance.

\section{Team Selection}

Significant attention regarding the project selection and team selection process has previously been reported ${ }^{1,2,3,4}$. Projects are created each year in four categories for student consideration and include:

- Industry Partnered

- Research Partnered

- Student Competitions/Student Organizations

- Independently Created

The students are advised at the start of the course that to excel, they must excel as a team. Individual performance alone will not be satisfactory. This is quite different than most academic course offerings. Due to the complexities of the projects, only high performing teams will excel. Average teams will reflect average performance and grades. Dysfunctional teams will be problematic and will encounter difficulties in meeting the course deliverables and project deliverables.

An online process has been created to better involve student consideration and team formation. This process has been very successful. This year 57 of 68 students (84\%) were placed on their $1^{\text {st }}$ preferred project with 13 of 14 team (93\%) student formed. Results since introduction of the online process may be reviewed in Tables 1 and 2 . At the start of the process, about $50 \%$ of the student teams were student formed as compared with instructor-formed teams. This has now grown to over $90 \%$ of teams are now student-formed.

\begin{tabular}{|l|c|c|c|c|c|c|}
\hline Year & $\begin{array}{c}\text { Total } \\
\text { Students }\end{array}$ & Total Teams & $\begin{array}{c}\text { Total } 1^{\text {st }} \\
\text { preference }\end{array}$ & $\begin{array}{c}\text { Total 2 } \\
\text { preference }\end{array}$ & $\begin{array}{c}\text { Total } 3^{\text {rd }} \\
\text { preference }\end{array}$ & $\begin{array}{c}\text { Total } \\
\text { preferred } \\
\text { placement }\end{array}$ \\
\hline $2009 / 10$ & 73 & 15 & $49(67 \%)$ & $10(14 \%)$ & $12(16 \%)$ & $71(97 \%)$ \\
\hline $2010 / 11$ & 68 & 14 & $52(76 \%)$ & $12(18 \%)$ & $1(2 \%)$ & $65(96 \%)$ \\
\hline $2011 / 12$ & 78 & 16 & $56(72 \%)$ & $11(14 \%)$ & $5(6 \%)$ & $72(92 \%)$ \\
\hline $2012 / 13$ & 68 & 14 & $57(84 \%)$ & $7(10 \%)$ & $0(0 \%)$ & $64(94 \%)$ \\
\hline
\end{tabular}

Table 1. Student Placement Results 


\begin{tabular}{|l|c|c|c|}
\hline Year & Total Teams & Student Formed Teams & Instructor Formed Teams \\
\hline $2009 / 10$ & 15 & $7(47 \%)$ & $8(53 \%)$ \\
\hline $2010 / 11$ & 14 & $8(57 \%)$ & $6(43 \%$ \\
\hline $2011 / 12$ & 16 & $12(75 \%)$ & $4(25 \%)$ \\
\hline $2012 / 13$ & 14 & $13(93 \%)$ & $1(7 \%)$ \\
\hline
\end{tabular}

Table 2. Team Formation Results

\section{Team Dynamics}

The selection process and team formation process has created a positive environment for teams to flourish. An attempt has been made to create student team that should be more engaged and motivated based upon student project and team preferences. Team satisfaction appears to be very good and team performance appears to be very good overall.

The typical Team Assessment and Self Assessment surveys are completed each quarter by the students and teams. In addition, a detailed Team Dynamics Survey (see Appendix 1) using a 5point Lickert scale has been conducted to assess team dynamics. All students are requested to complete the detailed Team Dynamics Survey as an individual.

It had been previously reported ${ }^{4}$ that this team formation process would hopefully eliminate dysfunctional teams. Although there were some Underperforming teams during the first three years of the process, no dysfunctional teams were noted. However, this observation was premature. There were two Underperforming and dysfunctional teams noted for the 2011/12 projects and teams. One team was instructor-formed with 4 students that could not be placed on any of their preferred projects and were placed on a Research partnered project. The other team was student-formed with an Industry partner. Both team had team leaders that had previous industry internship experience. However, both teams suffered from dysfunctional team leaders and teams with significant unresolved conflicts, poor team performance, and a painful experience personally expressed by multiple team members. These observations have served as a catalyst to further explore the role and importance of team leaders with the hopes of better addressing these situations with future teams.

\section{Team Leadership}

A voluntary survey (see Appendix 2) of all 2012/13 Capstone students was conducted with 23 of 68 responding for the 2012/13 class at the start of the course to address Course Expectations. This survey was administered to better understand expectations. A summary of student comments is as follows:

What are your expectations from your team in terms of performance and outcomes?

- Resolve conflicts

- Work well together

- All perform equally, each member should participate and carry their own load 
- Meet goals

- Utmost commitment and dedication

- Deliver a final product that meets requirements

What are you expectations from your team leader?

- Organize team and resolve conflicts

- Organize meetings, monitor all team members

- No power trips

- Leadership

- Coordination

A survey of the team leaders (see Appendix 3) for the 2012/13 projects has been conducted with 14 of 14 responding. All 14 team leaders volunteered for the position and were confirmed by the team through an informal process for each team. Of the 14 team leaders, 10 have indicated previous internship experience either in Industry or Research and one has indicated previous military experience.

From the team leader survey the primary role of the team leader is described as:

- Project planning documents

- Review and submittal of course deliverable documents

- Motivate

- Facilitate

- Assign responsibilities

- Maintain communication

- Organization and Coordination

Team leaders have indicated that they enjoy:

- The responsibility of leading the team

- Sense of accomplishment

- Project management

- Guide the team

- Communication

- Ability to interact with everyone on the team

Team leaders have indicated that they dislike:

- Poor work habits by some team members

- Burden of paperwork

- Not enough time for project management

- Pressure of team performance and achievements

- Not being able to focus on specific project tasks

- More difficult and time consuming than being a regular team member 


\section{Team Effectiveness}

An assessment of Team Dynamics has been completed for the 2012/13 projects after the Fall quarter. It should be noted that this may be premature in that the projects and teams must still complete the Winter and Spring quarters. All teams will continued to be followed as the course and the projects progress.

High Performance teams and Underperforming teams have been identified for the Fall quarter. There are three High Performing teams and two Underperforming teams that have been identified with assistance from independent faculty and staff review for the Fall quarter.

With the exception of the two Underperforming teams, all teams are performing well. A review of Team Dynamics Surveys confirms good team satisfaction with most Lickert scores at 4 or 5 with an overall score of 4.37 .

Of the High Performance teams, excluding team leaders, all team members scored their descriptions as a 4 or 5 with very few exceptions with an overall score of 4.67. The team leaders for these team however appear to be more critical with scores as low as 2 for some items with an overall score of 4.46. It should be noted that all three team leaders have previous Industry or Research internship experience.

Of the Underperforming teams, excluding team leaders, all team members also scored their descriptions as a 4 or 5 with very few exceptions with an overall score of 4.35. Very good team satisfaction is noted despite the underperformance. No dysfunctional team characteristics have been observed. The team leaders do not appear to be as critical as the High-performing teams with an overall score of 4.41 and actually scoring higher than the team overall. It should also be noted that both team leaders have had no previous or current internship experience.

\section{Conclusions}

The role of team leadership on Capstone teams appears to be significant and does appear to impact team performance. The leadership role on the Capstone project may be described as informal with no formal direct authority or responsibility on the team. There is a lack of hierarchal reporting or management structure as may be found professionally. This creates a unique environment for the team and team leader.

Detailed surveys have been conducted with 14 student teams and their team leaders for the current academic year. Good overall team satisfaction is observed and confirmed through survey instruments.

A review of High Performance and Underperforming teams over the past four academic years has been conducted and team leadership examined.

The intent of this paper was to examine the current informal team leadership role with a desire to provide improved guidance and support. 
It appears that teams may benefit with team leaders that have good organizational skills, good communication skills, good technical expertise, and desire a sense of responsibility.

The role and expectations for a good team leader is as follows:

- Maintains focus for self and the team objectives

- Ensures a collaborative team environment

- Motivates and exerts influence on the team

- Demonstrates and contributes technical expertise

- Ensures that the team sets priorities and assigns responsibilities

- Exhibits fairness, humility, and trust

- Maintains communication within the team and all external partners

- Has a desire to develop and demonstrate project management skills in terms of organization and coordination

Of the two Underperforming teams examined this year, both have team leaders with no internship experience. This observation should be examined more closely in future studies. It does appear that teams may benefit with team leaders that have had some internship experience. However, internship experience is not a guarantee of success. There have been two dysfunctional teams over the past four years. Both teams had team leaders with internship experience. However, both team leaders failed to meet any of the criteria detailed above regarding the role and expectations for a good team leader. Unfortunately, it appears that dysfunctional team leaders may result in dysfunctional teams.

The role of the team leader will continue to be an informal role and is much more than an administrative role. This role has been undertaken by students that desire a greater sense of responsibility and either volunteer or are selected by their team members. Guidance may now be offered at the start of the team formation process and team leadership selection regarding the role and expectations for a good team leader. Students and teams should also be aware that poor team leadership performance and characteristics may result in poor and dysfunctional team performance.

\section{Bibliography}

1. Laguette, Stephen W. Development of a Capstone Design Program for Undergraduate Mechanical Engineering. Proceedings of the 2007 ASEE Annual Conference \& Exposition.

2. Laguette, Stephen W. Integration of Industry Partners into a Capstone Design Program. Proceedings of the 2008 ASEE Annual Conference \& Exposition.

3. Laguette, Stephen W. The Development of High Performance Capstone Project Teams and the Selection Process. Proceedings of the 2010 ASEE Annual Conference \& Exposition.

4. Laguette, Stephen W. Progress Report -The Development of High Performance Capstone Project Teams and the Selection Process. Proceedings of the 2011 ASEE Annual Conference \& Exposition.

5. Laguette, Stephen W. Assessment of Project Completion for Capstone Design Projects. Proceedings of the 2012 ASEE Annual Conference \& Exposition.

6. Katzenbach, Jon R. and Smith, Douglas K. The Wisdom of Teams: Creating the High Performance Organization. Boston: Harvard Business School Press, 1993

7. Katzenbach, Jon R. and Smith, Douglas K. The Discipline of Teams. Boston: Harvard Business School Press, 1993

8. Lencioni, Patrick. The Five Dysfunctions of a Team. Jossey-Bass, 2002 
9. Zaccaro, Stephen and Rittman, A. , Marks, M. Team leadership. The Leadership Quarterly. 12 (2001) 451483.

10. Lafasto, Frank and Larson, C. When Teams Work Best. Sage Publications, 2001.

11. Singh, Anup K. and Muncherji, N. Team Effectiveness and Its Measurement: A Framework. Global Business Review, 8:1 (2007): 119-133.

12. Zemke, Diane and Zemke, S. Identifying Roles and Behaviors of Informal Leaders on Student Design Teams. Proceeding of the 2008 ASEE Annual Conference \& Exposition.

13. Ozgen, Sibel and Alabart, J. , Medir, M. A Team Leader Selection Process for Project-Based Learning Experiences. Proceeding of the 2008 ASEE Annual Conference \& Exposition.

14. Zafft, Carmen, and Adams, S., Matkin, G. Measuring Leadership in Self-Managed Teams Using the Competing Values Framework. Journal of Engineering Education, July 2009, 273-282.

15. Wilding, W. Vincent and Knotts, T.,Pitt, W., Argyle, M. Developing and Assessing Leadership in Engineering Students. Proceedings of the 2012 ASEE Annual Conference \& Exposition. 
Appendix 1.

Name

Team

Date

\section{TEAM DYNAMICS SURVEY}

Not Very

Descriptive
Very

Descriptive

1. Our purpose and goals as a unit are clear.

$\begin{array}{lllll}1 & 2 & 3 & 4 & 5\end{array}$

2. All important tasks have been assigned to individual team members.

3. Team meetings are productive.

4. We communicate well with each other.

5. We know each other's strength and skills.

6. We strongly agree on our priorities.

7. Team members clearly understand their responsibilities.

$\begin{array}{lllll}1 & 2 & 3 & 4 & 5\end{array}$

$\begin{array}{lllll}1 & 2 & 3 & 4 & 5\end{array}$

$\begin{array}{lllll}1 & 2 & 3 & 4 & 5\end{array}$

$\begin{array}{lllll}1 & 2 & 3 & 4 & 5\end{array}$

8. We operate efficiently.

$\begin{array}{lllll}1 & 2 & 3 & 4 & 5\end{array}$

9. We trust each other.

$\begin{array}{lllll}1 & 2 & 3 & 4 & 5\end{array}$

10. We capitalize on each other's strengths and skills.

$\begin{array}{lllll}1 & 2 & 3 & 4 & 5\end{array}$

11. We have specific and measurable objectives.

$\begin{array}{lllll}1 & 2 & 3 & 4 & 5\end{array}$

12. Team members clearly understand each other's roles.

$\begin{array}{lllll}1 & 2 & 3 & 4 & 5\end{array}$


Appendix 1.

Not Very

Very

Descriptive

Descriptive

13. We monitor our progress and results.

1

2

3

4

5

14. We enjoy working together.

1

2

3

4

5

15. We follow through on our plans and

12

3

4

5 priorities.

16. We all have opportunities to contribute.

17. We solve problems and make decisions effectively.

$\begin{array}{lllll}1 & 2 & 3 & 4 & 5\end{array}$

18. We help each other.

$\begin{array}{lllll}1 & 2 & 3 & 4 & 5\end{array}$

19. We are known for our ability to achieve $\begin{array}{lllll}1 & 2 & 3 & 4 & 5\end{array}$ high-quality results.

20. We work enthusiastically and energetically on any problem we tackle.

21. Leadership influence is exercised by $\begin{array}{lllll}1 & 2 & 3 & 4 & 5\end{array}$ more than one member of the team.

22. We coordinate our activities well with external resources.

$\begin{array}{lllll}1 & 2 & 3 & 4 & 5\end{array}$

23. There is a positive atmosphere on our team.

$\begin{array}{lllll}1 & 2 & 3 & 4 & 5\end{array}$

24. We are improving as a team.

$\begin{array}{lllll}1 & 2 & 3 & 4 & 5\end{array}$


Appendix 2.

\section{ME189 Course Expectations}

1. What are your expectations in terms of personal experiences or outcomes from your project?

2. What are your expectations from your team in terms of performance and outcomes?

3. What are your expectations from your team leader?

4. What are your expectations in terms of support from your Industry or Research Partner?

5. What are your expectations in terms of support from your TA?

6. What are your expectations from the support staff and facilities?

7. What are your expectations in terms of personal experiences and outcome from the course?

8. What are your expectations in terms of support and outcomes from your instructor?

9. What should your instructor provide in terms of "teaching” for this course? 
Appendix 3.

\section{ME189 Team Leaders Survey}

Name:

Team:

1. How was the Team Leader selected for your team?

2. What is your primary role as the Team Leader?

3. What do you enjoy most in role as the Team Leader?

4. What do you dislike most in role as the Team Leader?

5. Describe any related past internship experience:

6. Any additional comments that you would like to add:

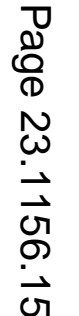

